\title{
REFLECTIE VAN EEN CHINESE SPIEGEL
}

De ronde, bronzen spiegel die Alfred Schoenlicht in 1925 schonk aan de Vereniging heeft een zwarte, glanzende patina. Hij verkeert in goede staat alhoewel enkele flinters brons ontbreken. In een jaarverslag van de Vereniging wordt deze spiegel 'als een buitengemeen fraai stuk' aangemerkt (afb. 1). ${ }^{2}$ De spiegel werd tentoongesteld op de Tentoonstelling van Chineesche Kunst in het Stedelijk Museum in Amsterdam (1925) en staat in de catalogus van die tentoonstelling beschreven (nr. 83). Hij staat eveneens afgebeeld in de derde premie-uitgave Chineesche Kunst uit 1927 (plaat XVII).

\section{Ontwikkelingsgeschiedenis van Chinese bronzen spiegels}

In tegenstelling tot goud en zilver dat makkelijk in rechthoekige vormen kon worden geslagen, was brons vooral geschikt voor de vervaardiging van voorwerpen met een ronde vorm.

De Chinese spiegel was onder meer een gebruiksvoorwerp. In het midden bevond zich een ronde, doorboorde knop, waardoor een koord of een riem kon worden gestoken dat als handvat diende (afb. 2). Ook kon de spiegel worden geplaatst op een standaard (afb. 3). De spiegel had niet alleen dagelijks nut, maar hield ook verband met (de zoektocht naar) onsterfelijkheid. Decoraties op spiegels hadden niet slechts een esthetische waarde, maar waren ook bedoeld om de kwade geesten te verjagen en de goede aan te trekken.

De voorkant werd altijd gepolijst zodat men zich kon spiegelen in het gladde oppervlak. Maar de gedecoreerde achterkant van de spiegel reflecteerde ook ideeën en geloofsovertuigingen. De symboliek en de patronen op de bronzen spiegels werden veelvuldig gekopieerd in later eeuwen. Ook al ondergingen het uiterlijk, de compositie van de decoraties en de rituele waarden van bronzen handspiegels grote veranderingen, altijd droeg de Chinese spiegel een grote symbolische of religieuze waarde. Vanaf de Han-dynastie (206 v.Chr.-220 n.Chr.) kregen spiegels een sterk mythologische en astronomische betekenis. In de Tang-dynastie (616-906) werden de spiegels andere magische krachten toegeschreven: ze zouden de kracht bezitten om mensen te laten flauwvallen of om voorspellingen te doen. Tot in de $12^{\mathrm{e}}-13^{\mathrm{e}}$ eeuw (zuidelijke Song-dynastie) werden de kosmische en astronomische symbolen op de spiegels gebruikt.

Inscripties verwezen naar een zoektocht naar succes in het huidige leven en naar harmonie met de spirituele krachten - ook in het hiernamaals. De spiegels werden vaak als grafgift meegegeven - tot persoonlijk nut van de overledene maar tevens ter bescherming van de dode tegen kwade geesten. Niet alleen in Chinese graven zijn deze spiegels teruggevonden $90 \mathrm{k}_{2}$ graven 28:02AM $_{3}$ van de Xiongnu, een oude vijand van het Han-China, bevatten de Chinese access 


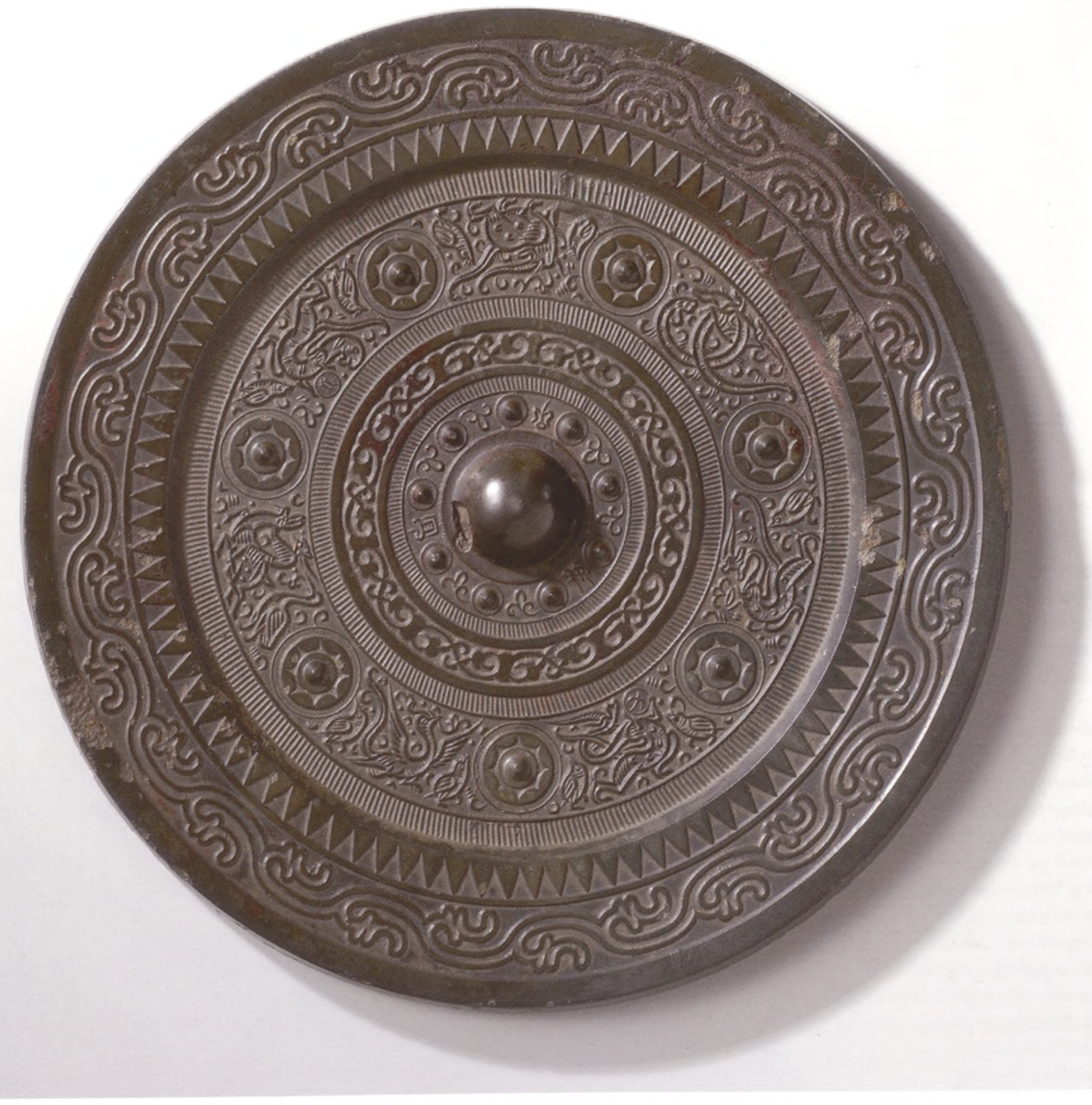

Afbeelding 1

Spiegel, brons, diameter $15,9 \mathrm{~cm}$., China, 200 v.Chr. - 200 n.Chr. Schenking van Alfred Schoenlicht in 1925, Rijksmuseum Amsterdam, collectie VVAK, AK-MAK 34 bronzen spiegels, met name de graven bij Noin Ula in het huidige NoordMongolie. Er is er zelfs één gevonden in de Tilla-tepe (heuvel van goud) in Bactria (het huidige Afghanistan).

De twee oudste bronzen spiegels uit China dateren uit de Shang-periode (Anyangfase, $13^{\mathrm{e}}-11^{\mathrm{e}}$ eeuw v.Chr.) en zijn afkomstig uit het graf van Lady Hao (1250 v.Chr.). De versieringen op de spiegels uit de Shang waren heel eenvoudig met een lijn- of stermotief.

In de daaropvolgende Zhou-periode (1045-256 v.Chr.) ontstonden geometrische en figuratieve versieringen die dikwijls waren geïnspireerd op bestaande geweven textielpatronen. Iets later, in de $4^{\mathrm{e}}-3^{\mathrm{e}}$ eeuw v.Chr., volgden de diermotieven: sterk gestileerde dierfiguren die in vloeiende lijnen overliepen in de geometrische achtergrond waardoor het lastig is de figuren te $e_{04: 28: 02 \mathrm{Am}}$ onderscheiden (afb. 4). 

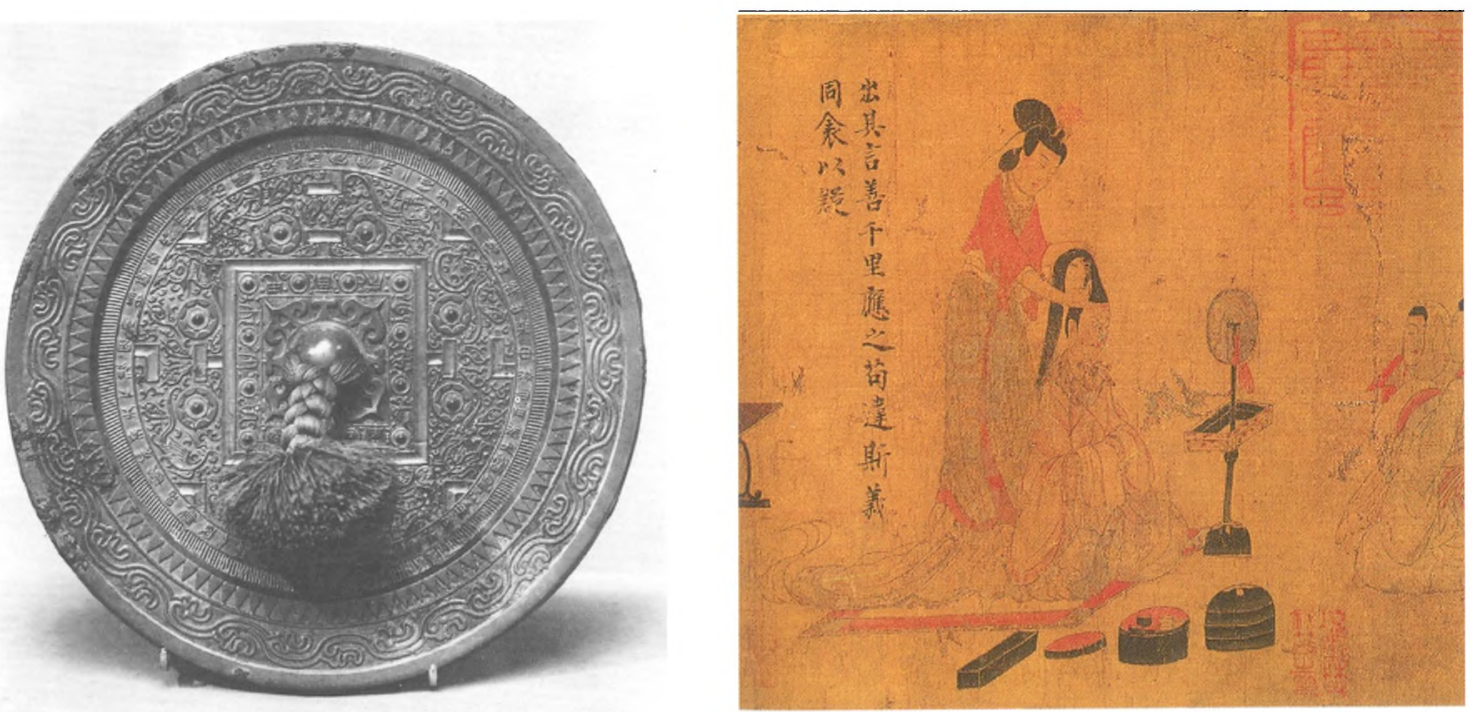

Afbeelding 2 (links) Bronzen TLV-spiegel met koord; Handynastie. Uit: M. Sullivan, The Arts of China

\section{Afbeelding 3}

Hofconcubine met dienares. Een bronzen spiegel op een standaard van gelakt hout. Detail van de schildering 'Vermaningen van de Hofinstructrice', toegeschreven aan $\mathrm{Gu}$ Kaizhi (ca. 344- Ca. 406), handrol, inkt en kleur op zijde. Uit: J. Rawson, The British Museum Book of Chinese Art

\section{Afbeelding 4}

Spiegel, brons, diameter $18,4 \mathrm{~cm}$., China, Zhou. periode, 500-200 v.Chr., Rijksmuseum Amsterdam, collectie WVAK,
In de Han-tijd kende het vervaardigen van deze spiegels een bloeiperiode. Daarbij bleven de bronsgieters gebruikmaken van traditionele geometrische motieven uit de Zhou-periode zoals de spiraalvormen en de aardse en hemelse symbolen. Kunst en literatuur uit de Han-dynastie wemelen van geesten, mythen en vreemde verschijningen. In de Huainanzi $\left(2^{\mathrm{e}}\right.$ eeuw v.Chr.) worden berggoden met een menselijk gezicht en een drakenlichaam beschreven. In deze periode omgeven heersers zich met zieners, sjamanen, astrologen en alchemisten. Men wilde de werking van de kosmos begrijpen,

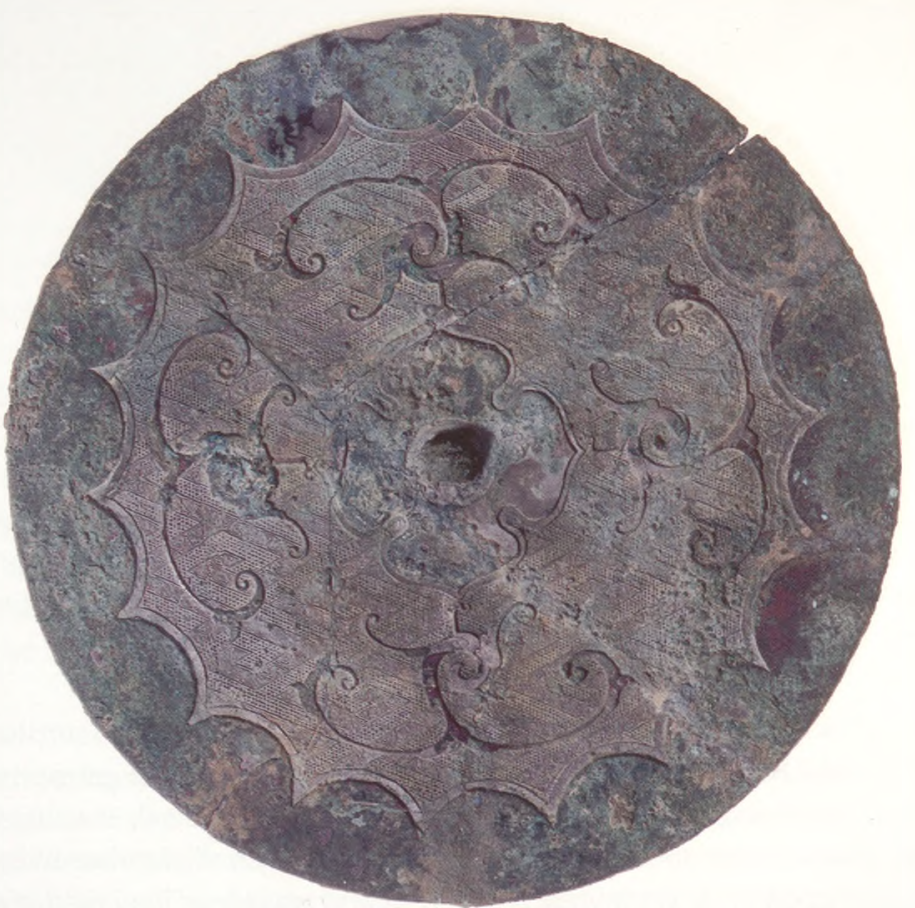


hetgeen leidde tot (kunst)voorwerpen die soms voorzien waren van een boodschap. Al snel verschenen op de Han-spiegels voor het eerst afbeeldingen van goden, onsterfelijken en boeddhistische figuren vaak samen met mythologische dieren. De decoraties waren strak geordend binnen cirkels en vertoonden - dikwijls - TLV-patronen (afb. 2). Deze Westerse naam is ontstaan omdat de belangrijkste motieven op deze kosmologische spiegels sterke overeenkomst vertonen met die Latijnse letters. Deze Han-spiegels dragen een zeer ordelijk beeld van de kosmos uit. Ze zijn gebaseerd op een kosmologisch diagram met een vierkant in het centrum, dat de aarde weergeeft. Binnen het vierkant zijn 12 knopen aangebracht. Het vierkant is omgeven door concentrische cirkels, elk opgebouwd uit vastomlijnde kenmerken.

In het centrale deel van de spiegel - tussen de knop en de buitenranden bevinden zich acht knopen alsook de dieren van de vier seizoenen die niet noodzakelijk op de goede positie staan, samen met de driepotige schildpad en de vreemde viervoetigen. De drie buitenste banden zijn uit betrekkelijk eenvoudig geometrische patronen opgebouwd, waarbij het repeterend karakter ervan de suggestie geeft van een permanent vloeiende beweging. De buitenste rand heeft een doorlopend drakenmotief. De tweede cirkel bestaat uit hondentanden. De derde cirkel is een neutrale cirkel met verticale lijntjes. De vierde cirkel bevat inscripties.

In de Han-spiegels zien we dat de figuren scherp zijn afgebeeld en dat elk element een vaste positie kent. Het universum wordt weergegeven als een goed geordend diagram in tegenstelling tot de meer magische, zwevende beelden van de eeuwen daarvoor. In de $1^{\mathrm{c}}$ eeuw na Christus werd deze strakke ordening losgelaten en werden er spiegels vervaardigd met een stercluster in de buitenrand, een ontwikkeling die zich voortzette in een niet onbelangrijk aantal spiegels van de Tang-dynastie.

Na de val van de Han werden veel voorwerpen die voorheen van brons werden gemaakt nu uit ander materiaal vervaardigd. Luxe eet- en drinkgerei, dat meegegeven werd als grafgift, en religieuze beelden maakte men voortaan van goud en zilver. De spiegels echter bleven altijd van brons vervaardigd. In de Tang-periode werden spiegels vaak versierd met landschapsornamenten en bladranken of bloemen van ingelegd zilver. De buitenrand had dikwijls de vorm van een acht-bladige bloem (afb. 5). In die tijd werd zoveel waarde aan

Afbeelding 5 Bloemvormige bronzen spiegel uit de Tang. dynastie. Uit: $M$. Scarpari, Het oude China

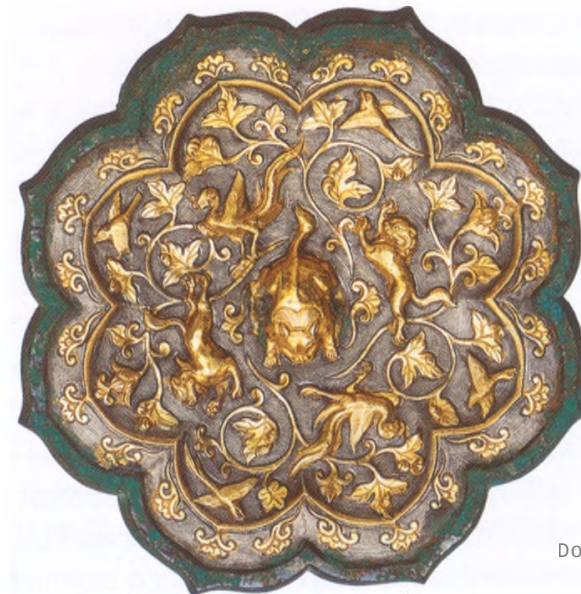




\section{Afbeelding 6}

Detail van de bronzen spiegel van Schoenlicht, schildpad met slang, AK-MAK-34

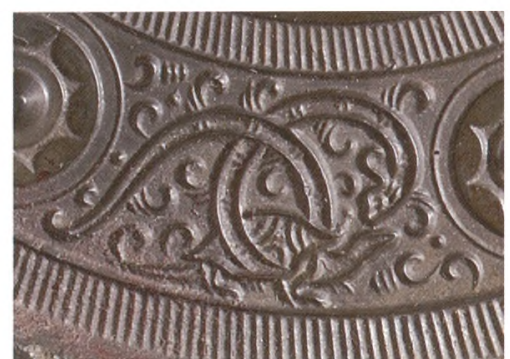

de spiegels gehecht dat ze zelfs konden dienen als kostbaar geschenk aan de keizer. De versiering bestond uit figuren van dunne goud- en zilverplaat, uitgesneden volgens de ajourtechniek en in een laklaag ingelegd. De knop werd beschouwd als een 'geluksparel', een symbool van een lang leven.

\section{De spiegel van Alfred Schoenlicht}

De spiegel die door Schoenlicht aan de Vereniging werd geschonken is mooi gedecoreerd en bestaat uit acht concentrische ornamentbanden en 15 rozetten. In het centrale deel zien we zeven rozetten met daartussen zeven mythologische dierfiguren. De knop is omringd door acht kleine rozetten waartussen drie karakters staan die een gunstig stemmende, voorspellende uitspraak vormen: yi zisun, 'geschikt voor nageslacht'.

De zeven dierfiguren in het centrale deel vormen het belangrijkste deel van de versiering. De dieren hebben hun kop naar rechts of naar links gedraaid alsof ze zijn vastgelegd in een dynamische beweging. Bij het ronddraaien van de spiegel lijkt vooral de versiering in de buitenste randen in een vloeiende, onafgebroken beweging te zijn. In kosmologische spiegels hebben dierfiguren altijd een symbolische, kosmologische betekenis:

- schildpad staat symbool voor water, het Noorden en de winter;

- feniks is symbool voor vuur, het Zuiden en de zomer;

- tijger voor metaal, het Westen en de herfst;

- draak voor hout, het Oosten en de lente.

Op onze spiegel staat geen tijger. Wel zien we een schildpad omkronkeld door een slang, ook een symbool voor het Noorden (afb. 6), en achtereenvolgens twee draken, een feniks, een kraanvogel met een vreemsoortige viervoeter, een griffioen en een eenhoorn.

Zoals we eerder zagen bij TLV-spiegels hoort er in de kosmologische ordening een vijfde element, het Centrum, uitgebeeld door een vierkant, dat symbool staat voor de aarde, maar op onze spiegel ontbreekt dat.

\section{Datering van onze spiegel}

De prachtige spiegel bevat decoratieve elementen die verwijzen naar de Oostelijke-Zhou-periode (770-256 v.Chr.). Zo is het tweede karakter van de inscriptie ( $z i$ ) geschreven op de wijze die men hanteerde in de $3^{C}$ eeuw voor Christus. En dierfiguren als feniksen en draken kwamen het meest voor op spiegels die aan het eind van de Oostelijke Zhou gemaakt zijn. We zien ook niet alle vier de symbolische dieren die symbool staan voor de elementen op de Han-spiegels. Maar ook al komen de dieren op onze spiegel niet geheel overeen met de elementen die zo kenmerkend zijn voor de TLMV de Han, toch zijn ze onmiskenbaar te herleiden als een exponent vanader ee access 
Han. Het is overduidelijk dat de dieren een kosmologische betekenis hebben. Vooral de ordening van de gehele compositie en de drie herkenbare buitenste randen (alleen de vierde cirkel met karkaters ontbreekt) maken ons duidelijk dat we hier kijken naar een spiegel uit de Han-dynastie.

\section{Schoenlicht}

Chinezen waren wars van het verzamelen van kunstvoorwerpen afkomstig uit graven. Grafgiften waren immers geen verzamelobjecten, maar geschenken aan de doden. De geest van de overledene moest worden voorzien van talrijke bezittingen. De eerste verzamelaars van Chinese grafgiften waren dan ook Westerlingen. In het begin van de $20^{e}$ eeuw kwamen veel grafgiften uit Noord-China in omloop omdat de grafvelden door de aanleg van het spoorwegnet waren omgewoeld. Alfred Schoenlicht, van Duits-joodse afkomst, was als verkoper van stoomlocomotieven naar China gegaan. Hij legde zich toe op het verzamelen van vooral vroeg-Chinese keramiek (Tang en Song). Begin jaren ' 30 verhuisde Schoenlicht naar Nederland. Zijn verzameling Aziatische kunst was in Nederland veruit de belangrijkste. Al voor de oorlog had hij zijn gehele verzameling in bruikleen gegeven aan het Museum of Fine Arts in Boston. Door de Tweede Wereldoorlog is het aantal joodse verzamelaars van Aziatische kunst in Nederland sterk afgenomen, vooral vanwege emigratie. Ook Schoenlicht ontkwam aan de Duitsers. In de oorlog kwam hij via Lissabon terecht in New York, waar hij uiteindelijk op 24 mei 1955 overleed. $^{3}$ Zijn verzameling is na zijn dood in Londen geveild en over de hele wereld verspreid geraakt.

Hij was een gedreven kracht voor de Vereniging, lid-voor-het-leven en oud-lid van het Algemeen Bestuur. Zijn giften, van onze spiegel maar vooral van Chinees porselein én ook een grote donatie aan het Aankoopfonds, zijn van groot belang geweest voor de Vereniging.

\section{Geraadpleegde literatuur}

- P. Buckley, The Cambridge Illustrated History of China, Cambridge (MA), 1996.

- J. Fontein, 'Het verzamelen van Aziatische Kunst in de twintigste eeuw', Aziatische Kunst 23/3 (1993), pp. 5-7.

- J. Fontein, 'De vroege jaren van de Vereniging', Aziatische Kunst 35/2 (2005), pp. 14-18.

- L. Hájek en W. Forman, A Book of Chinese Art. Four thousand years of sculpture, painting, bronze, jade, lacquer and porcelain, Londen, 1966.

- J. Hildebrand, Erfenis van oude culturen. China, Alphen aan den Rijn, 1987.

- J. Rawson, The British Museum Book of Chinese Art, New York, 1996.

- F. Salviati, 'Pre-Han Chinese Mirrors', Aziatische Kunst 27/1 (1997), pp. 21-28.

- W. Speiser, China. Geist und Gesellschaft, Baden-Baden, 1974.

- M. Sullivan, The Arts of China, Berkeley/Los Angeles, 1984, 3e druk.

- W. Watson, The Art of China to AD 900, New Haven, 1995.

\section{Noten}

1. Met dank aan de heer W.L. Harthoorn voor zijn waardevolle taalkundige adviezen.

2. Jaarverslag nr. 5, over de jaren 1927-1929, pp. 15-16. Archiefstuk VVAK, nr. 15.

3. Bulletin WVAK., Derde serie, nr. 5 (1955). 